\title{
Vivendo a gestação dentro de um sistema prisional
}

\author{
Lisandra Paim Militão Rosimery Barão Kruno
}

\begin{abstract}
RESUMO
Trata-se de um estudo qualitativo que buscou conhecer a vivência de gestantes detentas em uma penitenciária feminina de Porto Alegre e desvelar como percebem a assistência de saúde oferecida nesta instituição. Participaram voluntariamente sete gestantes que se encontravam no terceiro trimestre da gravidez. A coleta de dados ocorreu através de entrevista semi-estruturada durante o mês de novembro de 2012. A análise dos dados baseou-se no método temático de Minayo de onde emergiram duas categorias: (a) vivendo a gestação atrás das grades e (b) avaliando o serviço de saúde penitenciário. Evidenciou-se que as gestantes reclusas possuem seus direitos constitucionais parcialmente atendidos quanto à assistência de saúde, referindo medo com relação ao tratamento pessoal que receberão durante o parto pelos profissionais.
\end{abstract}

Descritores: Gestação, Mulheres, Sistema Prisional.

\section{Living pregnancy within a prison system}

\begin{abstract}
This qualitative study aimed to know the experience of pregnant convicted women in a women's prison in Porto Alegre and reveal how they perceive the health care offered at this institution. Participated in this study voluntarily seven women who were in the third trimester of pregnancy. The data were collected through semi-structured interviews during the month of November of 2012. Data analyses were based on the thematic method of Minayo where two categories became clear: (a) experiencing pregnancy behind bars and (b) assessing prison health care. It was shown that pregnant inmates have partially met their constitutional rights regarding health care, showing concern regarding the personal treatment they will receive during childbirth by the healthcare professionals.
\end{abstract}

Descriptors: Pregnancy, Women, Prison System.

${ }^{1}$ Graduada em Enfermagem pelo Centro Universitário La Salles (UNILASALLE), Canoas, RS, Brasil.

${ }^{2}$ Mestre em enfermagem pela Universidade Federal do Rio Grando do Sul (UFRGS), Porto Alegre, RS, Brasil. 


\section{Introdução}

Em 1983 foi legitimado, pelo Ministério da Saúde, o Programa de Atenção Integral à Saúde da Mulher (PAISM) que se propunha a ampliar e a qualificar as ações relacionadas à saúde feminina para além da parturição, contemplando entre outros aspectos, as disparidades relacionadas ao gênero, à violência doméstica, às condições de saúde das mulheres negras, indígenas, trabalhadoras rurais, bem como da mulher em sistema prisional. Este programa tinha como principais objetivos a redução dos índices de morbimortalidade feminina e a melhoria nas condições de saúde dessa população até então à margem da sociedade brasileira. ${ }^{1}$

Atualmente, no Rio Grande do Sul, as mulheres representam $51,33 \%$ da população total, sendo que, $7 \%$ são presidiárias. Destas, em torno de $70 \%$ possuem entre 18 e 35 anos de idade, ou seja, estão na plenitude da sua fase reprodutiva. Foi constatado que o principal motivo de prisão entre as mulheres nesta faixa etária é o envolvimento com 0 tráfico de drogas. ${ }^{2,3}$ Logo, não é incomum a permanência de gestantes dentro das instituições prisionais.

A maioria dos presídios brasileiros possui problemas referentes à superlotação e péssimas condições estruturais e de salubridade, predispondo a proliferação ou agravamento de diversas doenças infectocontagiosas, traumas, doenças crônico-degenerativas, além de transtornos mentais. Em algumas instituições as celas são improvisadas como enfermarias, dispondo de poucos equipamentos e profissionais qualificados. A carência de escolta policial dificulta que as presidiárias sejam levadas para tratamentos de saúde nos hospitais de referência. Há falta contínua de medicamentos e os tratamentos para diversas doenças acabam se reduzindo à prescrição de analgésicos para alívio dos sintomas. Praticamente inexiste o pré-natal e os programas voltados à prevenção dos cânceres de colo de útero e de mamas. ${ }^{4}$

Essas situações, que afetam quase todas as mulheres em sistema prisional, ficam ainda mais graves quando elas se encontram grávidas, tendo em vista a maior fragilidade física e emocional própria deste período. ${ }^{5}$

Embora a gestação seja um fenômeno fisiológico é consenso entre os profissionais de que podem surgir alguns problemas no decorrer desta fase, principalmente se tratando de gestantes privadas de liberdade. É possível que essas mulheres já ingressem no sistema prisional com algumas disfunções físicas ou emocionais prévias, condizentes com sua situação de vulnerabilidade social. Não obstante, esse quadro poderá se agravar ainda mais nas condições pouco saudáveis oferecidas nestas instituições.

Em 2003 foi instituído o Plano Nacional de Saúde no Sistema Penitenciário (PNSSP), que teve por objetivo garantir acesso à saúde das pessoas privadas de liberdade, oferecendo ações e serviços de atenção básica dentro das unidades prisionais. Essas ações devem ser desenvolvidas por equipes multiprofissionais para prevenção e para promoção da saúde, incluindo o direito ao pré-natal às detentas grávidas. ${ }^{6}$

É indiscutível que toda mulher necessite de maior cuidado durante a gravidez por conta das grandes mudanças que ocorrem em seu corpo e em seu estado emocional neste período. Alguns fatores como: condições de higiene, relações interpessoais, afetivas e aspectos ambientais são variáveis importantes que podem interferir na qualidade do desenvolvimento gestacional, com reflexos no parto e nas condições de saúde do recém-nascido.

A partir do contexto apresentado, este estudo teve por objetivos conhecer a vivência de gestantes dentro de um sistema prisional, bem como desvelar como percebem a assistência de saúde oferecida nesta instituição.

\section{Metodologia}

Trata-se de uma pesquisa qualitativa, descritiva e exploratória.

O método qualitativo faz inferência a valores, subjetividades e permite aprofundar conhecimentos sobre um grupo de pessoas com características específicas, tais quais as gestantes privadas de liberdade. ${ }^{7}$

As participantes foram sete gestantes detentas na Penitenciária Estadual Feminina Madre Pelletier, localizada em Porto Alegre. 0 critério para entrevistar este número de gestantes ficou na dependência da saturação de dados e nas condições oferecidas pela instituição.

O processo de saturação de dados ocorre quando o pesquisador percebe, durante a coleta de dados, que as informações de novos participantes tornaram-se redundantes para as reflexões analíticas, limitando aí o número de entrevistas a serem realizadas. ${ }^{8}$ 
Como critérios de inclusão foram considerados: gestantes procedentes ou não de outra instituição prisional; idade gestacional condizente com o terceiro trimestre; participação voluntária ao estudo e assinatura do Termo de Consentimento Livre e Esclarecido.

Das 8 (oito) gestantes detentas na penitenciária, foi excluída apenas 1 (uma) que não se encontrava no terceiro trimestre de gestação e que não estava alojada na galeria específica para gestantes com essa idade gestacional. As demais grávidas aceitaram em participar das entrevistas voluntariamente e em assinar o Termo de Consentimento Livre e Esclarecido. Portanto, não houve critérios de perda.

Primeiramente, foi agendado um encontro com a coordenação do serviço para acordar detalhes sobre os dias e horários mais adequados para as entrevistas, presença ou não de um agente penitenciário, entre outras peculiaridades.

Para a coleta dos dados foi reservada uma sala localizada no setor administrativo, onde as entrevistas pudessem ocorrer de modo individual e sem a presença de agentes penitenciários. A seguir, o material gravado foi fidedignamente transcrito.

A análise baseou-se no método temático, seguindo as etapas de pré-análise, exploração e tratamento dos dados, inferência e interpretação,7 de onde emergiram as seguintes categorias: a) Vivendo a gestação atrás das grades. b) Avaliando o serviço de saúde penitenciário.

Com relação aos aspectos éticos, esta pesquisa foi aprovada pelo Comitê de Ética e Pesquisa do Centro Universitário La Salle, em novembro de 2012, sob o n 140.224 e pela SUSEPE/RS (Superintendência dos Serviços Penitenciários), em setembro de 2012, levando em consideração todos os critérios da Resolução 196/96. ${ }^{9}$

Para cada participante foi esclarecido o tema de pesquisa, seus objetivos, os critérios de sigilo e anonimato, convidando-a a participar do estudo de modo voluntário e a assinar o Termo de Consentimento Livre e Esclarecido.

$O$ anonimato dos dados pessoais foi garantido, substituindo seus nomes reais pela letra $G$ (gestante) seguido do número de ordem das entrevistas, tais como: G1, G2, G3 e assim sucessivamente. As entrevistas foram guiadas por um instrumento contendo questões semi-estruturadas e gravadas através de um aparelho MP4, o que durou em média quarenta minutos cada. Os arquivos permanecerão guardados por cinco anos, sendo inutilizados após este prazo, conforme a recomendação da Lei dos Direitos Autorais 9.610/98. ${ }^{10}$

\section{Resultados e discussões}

\section{Caracterização do cenário da pesquisa e das participantes}

A penitenciária feminina Madre Pelletier, localizada na região metropolitana de Porto Alegre, possui uma galeria denominada de "Creche" com vinte e três leitos para gestantes a partir do oitavo mês de gravidez e puérperas com seus bebês. As gestantes de várias regiões do Estado costumam ser transferidas para esta instituição, já que em outras cidades do Estado ainda não há uma galeria apropriada para o acolhimento materno-infantil. 3,11

O ambulatório dessa penitenciária conta com uma equipe de saúde composta por médico clínico, enfermeira, técnicos de enfermagem e uma médica ginecologista e obstetra que realiza consultas duas vezes por semana. Os casos mais complexos e os partos são encaminhados para um hospital referenciado da rede pública.

As participantes têm em média 27 anos, são predominantemente brancas e solteiras. Nenhuma completou o ensino fundamental. As ocupações exercidas pelas mulheres antes da reclusão foram: atendentes de loja, auxiliares de serviços gerais, operadoras de caixa, auxiliares de cozinha e manicures. Quanto à paridade, todas são multigestas e multíparas, com uma média de dois filhos já nascidos. Entre os problemas ocorridos na gravidez atual relataram: a anemia, o trabalho de parto prematuro, um caso de pancreatite e um caso de hepatite (não especificada pela gestante), mas detectada no pré-natal. Nenhuma entrevistada admitiu doenças pré-existentes à gravidez.

As gestantes, ao ingressarem na penitenciária, são encaminhadas para a coleta de exames laboratoriais, seguida de uma consulta de pré-natal ao mês. Já as gestantes de alto risco realizam o acompanhamento em hospitais de referência (HR), mediante escolta vigiada.

A Organização Mundial da Saúde recomenda que toda gestante de baixo risco tenha, pelo menos, seis consultas de pré-natal durante toda a gravidez. Porém, as grávidas de maior risco devem realizar consultas mensais até a $28^{a}$ semana, quinzenais entre $28^{\mathrm{a}}$ e a $36^{\mathrm{a}}$ semanas e semanais até o nascimento do bebê.12 As gestantes entrevistadas admitiram realizar o pré-natal antes mesmo da reclusão, embora de modo irregular. 


\section{Vivendo a gestação atrás das grades}

A solidão e a saudade dos familiares, principalmente dos filhos que ficaram sob a guarda de vizinhos ou parentes, foram os sentimentos mais salientados:

[...] não é o fato de eu tá aqui, é o fato de eu não ter notícia da minha filha. Eu tô seis meses presa sem advogado, sem visita (G1).

[...] eu tenho mais cinco lá na rua precisando de mim, né. Ah, eu tenho o meu pai que surgiu um câncer nele a um mês do nada. Então pra mim é muito difícil. Eu fiz esse erro por burrice na minha vida e, no caso, eu me sinto muito mal porque eu devia de tá lá entendeu? (G7).

Muitas mulheres que estão em sistema prisional são responsáveis pelo sustento de seus filhos e ficam angustiadas com o que pode vir a acontecer com eles; até mesmo na possibilidade do envolvimento dos mesmos com a criminalidade no futuro. Esse é um dos aspectos mais difíceis entre as mulheres privadas de liberdade e que segue invisível ao tratamento de questões ligadas ao encarceramento. ${ }^{13}$

A fala de G7 também demonstra que há um profundo sentimento de culpa e uma necessidade muito grande de se redimir através do trabalho. Interpreta como se todos os demais acontecimentos tivessem relação direta com o seu erro. O aparecimento do câncer em seu pai é um exemplo disso, conforme ilustrado em sua fala.

Outra questão comentada é que seus companheiros não são assíduos às visitas, pois também se encontram envolvidos com o crime e estão foragidos da polícia.

Sabe, ele caiu junto comigo, só que daí como ele deu o nome falso e eu tava foragida e não sabia e tava com os meus documentos, acabei sendo presa [...] (G1)

Recebo visita só da minha sobrinha, porque o resto, todos estão presos também (G4)

O fato é que, por não existirem serviços penitenciários com estruturas adequadas para gestantes em outras regiões do Estado, estas acabam sendo transferidas para locais distantes da família, dificultando as visitações. No entanto, estatisticamente, os homens reclusos costumam receber mais visitas de suas companheiras, mães e filhas, 0 que reafirma que a mulher continua desempenhando o papel de principal cuidadora da família na sociedade. ${ }^{14}$

Além da solidão, as gestantes também referem ociosidade. $O$ trabalho dentro da penitenciária minimiza essa sensação. Entretanto, devido às condições estruturais do próprio ambiente, associado ao desconforto físico característico do final da gestação, essa possibilidade torna-se remota.

Ah, era bom fazer um trabalho pra gente sair um pouquinho da cela, [...] a gente só fica comendo, não tem o que fazer! Daí acaba ás vezes até ficando doente (G6).

A oportunidade de trabalhar ou participar de algum curso durante a reclusão conta tempo para a remissão da pena, além de facilitar a reinserção da detenta na sociedade. ${ }^{15}$

Em muitas unidades prisionais não existe qualquer programa voltado à prática de atividades físicas, laborais e recreativas, o que seria fundamental para a preservação da saúde mental e física dessas mulheres, além de prevenir algumas doenças. ${ }^{5}$

As participantes também ressaltaram medos e dúvidas, não propriamente ao processo físico do parto, mas quanto ao modo como esse processo poderá acontecer dentro do contexto penitenciário, tais como o local onde o nascimento acontecerá, o tratamento que receberão por parte dos profissionais no hospital de referência e quanto aos limites de contato com o recém-nascido.

Quanto ao local onde o parto se dará mencionaram duas possibilidades: ir para um hospital de referência (HR), que Ihes é desconhecido, ou parir na penitenciária acidentalmente.

O Programa Rede Cegonha, legitimado em 2011 pelo governo federal, em consonância com a Lei $n^{\circ}$ 11.634, de 27 de dezembro de 2007, dispõe que é direito de toda gestante (incluindo às mulheres detentas), conhecer e realizar vinculação prévia com a maternidade onde ocorrerá o parto. ${ }^{16,17}$ 
Portanto, os profissionais da instituição prisional poderiam oportunizar às gestantes essa possibilidade, informando sobre os hospitais de referência (HR), mesmo que através de material áudio visual, esclarecendo dúvidas e minimizando ansiedades.

Conhecer antecipadamente o local onde se dará o parto possibilita à parturiente maior confiança e melhores condições fisiológicas durante a parturição, beneficiando principalmente ao recém-nascido. Estudiosos do período perinatal afirmam que experiências traumáticas vivenciadas pela grávida são memorizadas pelo feto, através de seu sistema neuro sensorial, predispondo-o a desequilíbrios físicos e emocionais que podem se manifestar em fases posteriores do desenvolvimento. ${ }^{18}$

Da mesma forma, o tratamento pessoal que receberão por parte dos profissionais durante a parturição também as preocupa:

[...] só acho ruim no hospital, porque tu fica acorrentada pelos pés até na hora de ganhar. Acho que vai ser difícil. Eu queria sair bem antes do parto; eu sei que isso não vai acontecer, então eu já tô me conformando (G4).

Em conversa informal com profissionais pertencentes a uma das maternidades de referência, os mesmos confirmaram esse procedimento, salientando que não se trata de uma rotina determinada pelo hospital e sim pela SUSEPE. Porém, não possuem interesse em recebê-las no centro obstétrico, pois entendem que as detentas são "até beneficiadas ao ficarem em pré-parto privativo". Essa afirmativa revelou uma postura profissional ostensivamente despreparada e discriminatória, que contradiz todas as premissas sobre humanização da assistência ao parto e nascimento.

Outra situação relatada pelas gestantes é que, caso o trabalho de parto ocorra após as 17h, não haverá profissionais da saúde presentes na instituição e nem sempre há escolta disponível para o transporte noturno. Não raro, nascimentos acontecem nas galerias, sem que haja pessoal devidamente preparado para atendê-los:

[...] outra vez que eu tive aqui, uma menina ganhou na escada, a gente até apelidou o bebê de escadinha (G2). [...] porque se tu diz pra funcionária que quer ir na enfermaria, daí tu pede duas, três vezes, leva um xingão. Então, eu já nem peço. Eu pego e fico quieta (G4).

A falta de recursos básicos do sistema prisional ou a desvalorização das queixas das gestantes por parte dos profissionais confere grave falha no que diz respeito aos direitos humanos, podendo repercutir em sérios danos à mãe e ao recém-nascido. ${ }^{5}$

Todavia, o Estado é responsável pela vida, pela saúde e pela dignidade da mulher presidiária e de sua criança como seres de direito. Não cabe que essas pessoas sejam punidas com a privação dos seus demais direitos humanos e de sua cidadania. ${ }^{19}$

Outro fator ansiogênico para a gestante detenta é que, mediante a necessidade de o bebê ficar internado em UTI neonatal, não poderá acompanhá-lo enquanto hospitalizado, devendo retornar para a penitenciária após a alta da maternidade.

Essa possibilidade é relativamente comum, gerando angústia especialmente à gestante de alto risco.

A maioria das entrevistadas referiu o quanto é importante a presença de seus filhos durante o período em que se encontram no sistema prisional. Dizem não se sentirem tão sós, oferecendo-lhes mais tempo e amor do que puderam proporcionar para os outros filhos que estão "lá fora".

Entretanto, nem todas as mulheres pensam da mesma forma, ou por considerarem a penitenciária um local inadequado para a criança ou para que possam continuar trabalhando, buscando assim a remissão de sua pena mais rapidamente. $O$ fato é que toda detenta ao ganhar seu filho, permanece na área denominada creche e nesta as crianças devem permanecer 24h na presença da mãe, impedindo-a de trabalhar dentro na instituição.

[...] ele não vai ficar aqui comigo né, porque se eu ficar na creche, eu vou ficar parada, sem fazer nada, sem ganhar remissão. Então o nenê vai pra casa e eu vou continuar trabalhando. (G7).

Além disso, toda condenada que cumpre pena em regime fechado poderá ter parte do tempo de execução de sua pena remida por trabalho ou estudo. A cada três dias trabalhados, representa um dia a menos de sua pena..$^{20,21}$ 
Por outro lado, o bebê afastado de sua mãe ficará impossibilitado de ser amamentado ou acalentado pela mãe, perdendo com isso alguns benefícios preciosos ao seu pleno desenvolvimento físico e emocional.

\section{Avaliando o serviço de saúde penitenciário}

As entrevistadas, ao ingressarem na penitenciária, realizam exames laboratoriais para logo iniciarem o pré-natal, 0 que inclui até duas ecografias obstétricas durante toda a gestação.

De modo geral, as gestantes avaliaram o serviço de saúde da instituição como muito bom e consideram-se bem assistidas durante o período em que os profissionais da enfermaria estão presentes:

\section{[...] eles tem o maior cuidado com as grávidas, isso é muito bom mesmo (G3).}

A finalidade do pré-natal é proteger a saúde do binômio mãe-feto, diagnosticando possíveis complicações, tratando ou encaminhando precocemente a gestante para atendimento especializado. A atenção aos aspectos psicossociais e educativos também deve ser contemplada, pois a adesão das mulheres às consultas depende em parte da acolhida prestada pelos profissionais de saúde. ${ }^{12}$

Todavia, embora as grávidas sejam bem acolhidas por este serviço, referem não dispor de orientações educativas relativas à preparação ao parto, amamentação e cuidados básicos com o recém-nascido. Na galeria "Creche", as mulheres mais experientes ajudam as mais novas na vivência da maternidade.

Apesar de o pré-natal ser bastante elogiado pelas gestantes, as mesmas reforçaram alguns pontos que as preocupam: a falta de profissionais de saúde após as $17 \mathrm{~h}$ e a ausência de uma assistência pediátrica neste período.

0 afastamento da criança doente para consulta sem a presença materna está ilustrado na fala de G2:

[...] não ouvi falar de pediatra aqui dentro. Aí fico pensando, se ela (a filha) chegar a adoecer, ter uma febre... eles vão me dar paracetamol e vai ficar naquilo ali? Porque eu ouvi falar que é eles que levam e a gente fica aqui, né! Imagina, acho que sou capaz de enlouquecer! (G2)

Á noite, as mulheres contam com a avaliação das agentes penitenciárias, que julgam não possuir capacitação suficiente para socorrê-las em situações mais emergenciais.

[...] na galeria tem várias grávidas de alto risco, tem ali as crianças, né! Porque muitas crianças passam mal à noite e os funcionários pra sair daqui não é fácil! (G4).

É irrelevante a necessidade de reestruturar e valorizar a qualificação dos profissionais que trabalham no sistema prisional, estabelecendo planos de carreira, bem como salários que os dignifiquem e os estimulem. As capacitações devem ressaltar todos os prejuízos humanos e sociais que são gerados quando não se cumprem os direitos das presas e de suas crianças com relação à saúde, educação e cidadania. ${ }^{19}$

A falta de profissionais capacitados, o despreparo dos agentes penitenciários para atender pequenos problemas, bem como a dificuldade de escolta e transporte durante a noite acaba por desqualificar um serviço que não apresenta continuidade em seus diferentes turnos de trabalho.

\section{Considerações finais}

O perfil das gestantes privadas de liberdade confirma o que outros estudos realizados no Brasil constataram: baixo nível de escolaridade, envolvimento com o tráfico de drogas, solteiras e multigestas. A maioria delas se torna mãe ainda adolescente sem o apoio familiar. A preocupação com os filhos que ficaram sob a tutela de um abrigo social ou vizinho é unânime e poucas recebem visitas dos mesmos, referindo solidão e descaso por parte dos "companheiros".

$\mathrm{O}$ trabalho institucional é um modo de reduzir a pena na expectativa de parirem seus filhos longe do cárcere e na maternidade de sua escolha. Ter um parto improvisado, sem a assistência adequada dentro da penitenciária ou ser algemada na mesa de parto parece um castigo que vai muito além da privação de ir ou vir. Não obstante, configura-se em violação grave contra a mulher e ao nascituro, no que tange ao respeito e dignidade durante a parturição. 
É válido lembrar que as pessoas privadas de liberdade possuem direitos e deveres constitucionalmente garantidos e que têm o SUS como base de assistência a sua saúde, tal qual qualquer outro cidadão. ${ }^{4,6,17}$ Portanto, médicos, enfermeiros e demais profissionais da saúde não estão lhes prestando nenhum favor em oferecer um cuidado digno e humano, bem como às suas crianças.

Inúmeros outros motivos de ansiedade por parte das gestantes foram relatados: a falta de profissionais capacitados para atendê-las à noite, escolta insuficiente para conduzi-las ao hospital caso necessitem; a não permanência com o bebê se este ficar internado na unidade neonatal e a ausência de um pediatra que acompanhe as crianças dentro da penitenciária. Nesses aspectos, a integridade física das mulheres e de seus filhos não está sendo de todo contemplada, exigindo maior atenção por parte do Estado.

Entretanto, o serviço de pré-natal da instituição foi considerado muito bom pelas entrevistadas, pois oferece consultas regulares, ecografias obstétricas e profissionais atenciosos, dedicados e "humanos". Isso faz crer que o que deveria ser uma regra nos serviços de saúde tornou-se uma exceção, comparado ao precário acolhimento que muitos profissionais oferecem às gestantes longe dos muros penitenciários. Em contrapartida, as gestantes em sistema prisional informam não receber nenhum tipo de orientação prática com relação ao preparo para o parto, amamentação e cuidados com 0 recém-nascido, o que lhes confere um prejuízo.

Com relação a isso, as Universidades, através de seus cursos na área da educação e da saúde, poderiam ofertar esse suporte ao serviço penitenciário, buscando cumprir a importante indissociabilidade entre ensino, pesquisa e extensão numa perspectiva interdisciplinar. Capacitar os profissionais, especialmente os agentes penitenciários, promover cursos profissionalizantes e atividades físicas às reclusas seriam importantes contribuições com vistas à ressocialização dessas mulheres, além de prevenir agravos ocasionados pelo tempo ocioso dentro das celas. A formação de grupos educativos para gestantes, para puérperas e consultas de puericultura poderiam ser atividades desenvolvidas por acadêmicos de diversos cursos como enfermagem, medicina, psicologia, entre outros, na condição de práticas supervisionadas ou atividades de extensão.

Neste ínterim, este estudo reafirma a necessidade de mudanças, não somente na estrutura do sistema prisional, mas, sobretudo, no pensamento de profissionais e da sociedade civil com relação ao modo como as penalidades têm sido aplicadas às mulheres privadas de liberdade. ${ }^{4} \mathrm{O}$ sistema penal atual reforça 0 estigma, a desumanização e restringe direitos básicos, instigando a revolta, quase sempre, revertida na recorrência do crime. ${ }^{15}$ As crianças nascidas neste contexto, quando ficam com suas mães, tornam-se vulneráveis a doenças e atrasos no desenvolvimento devido às condições precárias do ambiente prisional e, se forem afastadas das mães logo após o parto, perdem por não desfrutarem do vínculo materno e por não serem amamentadas como lhes seria de direito. ${ }^{19}$

Dessa forma, observa-se que os instrumentos legais que primam pela reeducação e pela saúde de gestantes encarceradas não se cumprem integralmente na prática, tornando evidente a falta de comprometimento político e institucional com sua reinserção na sociedade.

\section{Referências bibliográficas}

1. Brasil, Ministério da Saúde. Assistência integral à saúde da mulher: bases para uma ação programática. Brasília, DF: Ministério da Saúde; 1984.

2. IBGE - Instituto Brasileiro de Geografia e Estatística. Primeiros dados do censo - 2010 [Internet]. Brasília, DF: Instituto Brasileiro de Geografia e Estatística; 2010 [acesso em 15 jun 2011]. Disponível em: http://www.ibge.gov.br/home/ estatistica/populacao/cens02010/caracteristicas_da_populacao/caracteristicas_da_populacao_tab_pdf.shtm

3. Susepe - Superintendência dos Serviços Penitenciários. Estatísticas - 2013 [Internet]. Porto Alegre: Susepe; 2013 [acesso em 14 jan 2013]. Disponível em: http://www.susepe.rs.gov.br/conteudo.php?cod_menu=31

4. Gustin EC. Mulher e saúde na prisão: a realidade nacional [Internet]. In:Anais do Encontro Nacional do Encarceramento Feminino; 2011; Brasília, BR. Brasília: Conselho Nacional de Justiça; 2011 [acesso em nov 2012]. Disponível em: http:/l www.cnj.jus.br/images/eventos/encarceramentofeminino/apresentacao.educardocrossara.pdf

5. Centro pela Justiça e pelo Direito Internacional, Associação Juízes para a Democracia, Instituto Terra, Trabalho e Cidadania, Pastoral Carcerária Nacional/CNBB, Instituto de Defesa do Direito de Defesa, Centro Dandara de Promotoras Legais Popular, et al. Relatório sobre as mulheres encarceradas no Brasil [Internet]. Botafogo; 2007 [acesso em ago 2012]. Disponível em: http://www.asbrad.com.br/conteúdo/relatório_oea 
6. Brasil, Ministério da Saúde. Plano Nacional de Saúde no Sistema Penitenciário. 2. ed. Brasília, DF: Ministério da Saúde; 2005.

7. Minayo MCS. Pesquisa social: teoria, método e criatividade. Petropólis, RJ: Vozes; 2010.

8. Fontanella BJB, Ricas J, Turato ER. Amostragem por saturação em pesquisas qualitativas em saúde: contribuições teóricas. Cad Saúde Pública. 2008;24(1):17-27.

9. Conselho Nacional de Saúde. Resoluções 1996 [Internet]. Brasília, DF: Conselho Nacional de Saúde; 1996 [acesso em 15 maio 2012]. Disponível em: http://conselho.saude.gov.br/resolucoes/reso_96.htm

10. Brasil. Lei $n^{0}$ 9.610, de 19 de fevereiro de 1998. Regula os direitos autorais, entendendo-se sob esta denominação os direitos de autor e os que lhes são conexos e dá outras providências. Diário Oficial da União. 20 fev 1998;Seção 1:3.

11. Viggiano FB, Gomes MJFP; Conselho Nacional de Política Criminal e Penitenciária. Presídio Central de Porto Alegre, Penitenciária Feminina Madre Pelletier e Instituto Psiquiátrico Forense Maurício Cardoso: relatório de visitas de inspeção. Brasília, DF; 2012 [acesso em set 2012]. Disponível em: http://portal.mj.gov.br/main.asp?View=\{E9614C8CC25C-4BF3-A238-98576348F0B6\}\&BrowserType=NN\&LangID=pt-br\&params=itemID\%3D $\{$ A5701978-080B-47B798B6-90E484B49285\}\%3B\&UIPartUID=\{2868BA3C-1C72-4347-BE11-A26F70F4CB26 $\}$

12. Brasil, Ministério da Saúde, Secretaria de Atenção à Saúde, Departamento de Atenção Básica. Atenção ao prénatal de baixo risco. Brasília, DF: Ministério da Saúde; 2012. (Série A. Normas e Manuais Técnicos. Cadernos de Atenção Básica, $\mathrm{n}^{0} 32$ ).

13. Neri HF, Oliveira MFL. A maternidade em situação de privação de liberdade: uma articulação sobre o sujeito do direito e o sujeito do desejo. In: Anais do 9. Seminário Internacional Fazendo Gênero: diásporas, diversidades, deslocamentos; 2010; Florianópolis, BR. Florianópolis: EDUFSC; 2010 [acesso em maio 2012]. p. 1-9. Disponível: http:// www.fazendogenero.ufsc.br/9/resources/anais/1278264260_ARQUIVO_fg9_texto_Heloneida.pdf

14. Escritório das Nações Unidas sobre Drogas e Crimes, Organização Pan-Americana de Saúde. Guia sobre gênero, HIVIAIDS, coinfecções no sistema prisional [Internet]. Brasília, DF: Escritório das Nações Unidas sobre Drogas e Crimes; 2012 [acesso em set 2012]. Disponível em: http://www.unodc.org/southerncone/pt/frontpage/2012/08/31-unodc-guiagenero-hiv-aids-sistema-prisional.html

15. Fernandes DC, Boczar S. A ressocialização do sentenciado a luz da dignidade humana: programas e atividades no presídio de Alfenas. Rev Âmbito Jurídico [Internet]. 2012 [acesso em nov 2012];15(105):[aproximadamente 1 p.]. Disponível em: http://www.ambito-juridico.com.br/site/index.php?n_link=revista_artigos_leitura\&artigo_id=9885

16. Brasil, Ministério da Saúde. Rede Cegonha [Internet]. Brasília, DF: Ministério da Saúde; [2011] [acesso em set 2012]. Disponível em: http://portal.saude.gov.br/portal/saude/gestor/visualizar_texto.cfm?idtxt=37082

17. Brasil, Ministério da Saúde, Secretaria de Atenção à Saúde, Departamento de Ações Programáticas Estratégicas. Legislação da saúde no sistema penitenciário [Internet]. Brasília, DF: Ministério da Saúde; 2010 [acesso em set 2012]. (Série E. Legislação de Saúde). Disponível em: http://bvsms.saude.gov.br/bvs/publicacoes/legislacao_saude_sistema_ penitenciario.pdf

18. Reichert E. Infância, a idade sagrada: anos sensíveis em que nascem as virtudes e os vícios humanos. Porto Alegre: Vale do Ser; 2008.

19. Brasil, Ministério da Justiça, Secretaria Especial de Políticas para as Mulheres, Grupo de Trabalho Interministerial. Reorganização e reformulação do sistema prisional feminino: relatório final [Internet]. Brasília, DF; 2007 [acesso em set 2012]. Disponível em: http://www.mpdft.gov.br/portal/pdf/unidades/promotorias/pdij/Publicacoes/RELATORIO_FINAL_-versao_97-2003.pdf

20. Regime Fechado [Internet]. São Paulo: JusBrasil; c2013 [acesso em nov 2012]. Disponível em: http://www.jusbrasil. com.br/topicos/293090/regime-fechado

21. Brasil. Lei no 12.433, de 29 de junho de 2011 [Internet]. Altera a Lei no 7.210, de 11 de julho de 1984 (Lei de Execução Penal), para dispor sobre a remição de parte do tempo de execução da pena por estudo ou por trabalho. Diário Oficial da União. 30 jun 2011 [acesso em nov 2012]; Seção 1:[aproximadamente 1 p.]. Disponível em: http://www.planalto. gov.br/ccivil_03/_Ato2011-2014/2011/Lei/L12433.htm. 


\section{Lisandra Paim Militão}

Endereço para correspondência - Rua Dr. Dias da Cruz, n. 92. Bairro Medianeira, CEP 90880-380, Porto Alegre, RS, Brasil.

E-mail: lisandrapm@yahoo.com.br

Currículo Lattes: http://lattes.cnpq.br/5939023327556034

Rosimery Barão Kruno - kruno@cpovo.net

Recebido em 16 de junho de 2013.

Publicado em 10 de março de 2014. 
